\title{
MORPHOLOGICAL CHARACTERISTICS AND MOTOR ABILITIES OF PHYSICALLY ACTIVE AND INACTIVE FEMALE HIGH-SCHOOL STUDENTS
}

\author{
Marijana Simić1 Jovan Vuković ${ }^{1}$, Saša Marković ${ }^{2}$, and Mila Vukadinović ${ }^{1}$ \\ ${ }^{1}$ Faculty of Sport and Physical Education, University of Novi Sad, Serbia \\ ${ }^{2}$ Faculty of Physical Education and Sport, University of Banja Luka, \\ Bosnia and Herzegovina
}

\section{SUMMARY}

On a sample of 72 girls from high school „Svetozar Miletic“ from Novi Sad, age $18 \pm 6$ months divided into two groups: physically active (at least 30 minutes of daily physical activities of moderate intensity) and insufficiently physically active (below average) was performed a research of transversal character with intent to determine whether there are statistically significant differences in morphological characteristics and motor abilities. The study applied 13 variables, five morphological (body height, body weight, body mass index, body fat percentage, $m$ muscle mass percentage) and 8 motorically (flamingo balance test, hand tapping, sit and reach, standing broad jump, from lying to sitting position for 30 seconds, bent arm hang, shuttle run 10x5 m and endurance shuttle run). Obtained results of multivariate analysis (MANOVA) indicate that there are statistically significant differences between the variables in morphological characteristics at level of $p=.02$ and motoric abilities at the level of $p=.00$, while univariate analysis (ANOVA) indicates, that in morphological characteristics there are only differences in the percentage of muscle mass, at the level of $p=.006$, while in motor abilities difference was determined in all variables.

Key Words: active, inactive, morphological characteristics, motor abilities.

\section{INTRODUCTION}

Physical activity is one of the criteria for assessing the health, while physical inactivity has been identified as the fourth leading risk factor for overall mortality which globally contributes to 3.2 million deaths per year (WHO, 2012).

Physical activity is associated with numerous health benefits (Bouchard, Blair, \& Haskell, 2012), and studies have shown that even small and moderate activity can contribute to the improvement of health status (Blair, 2005), both for adults and for children and adolescents (Camero, Hobbs, Stringer, Brancum, \& Taylor, 2012). Physical activity is particularly important for children and youth because it promotes healthy growing up and affects social (Malina, Bouchard, \& Baror, 2004) and cognitive development (Biddle \& Asare, 2011). In most countries, children and adolescents are not active enough (Guthold, Cowan, Auten- rieth, Kann, \& Riley, 2010; Hellal et al., 2012; Troiano et al., 2008).

Although positive effect of physical exercise on physical and mental health is scientifically proven (Byrne \& Byrne, 2003; Heyward, 1991; Plonczynski, 2000; Weinberg \& Gould, 2007), and indirectly on the overall quality of life, statistics show that most people are not sufficiently physically active. Physical inactivity among young people has increased dramatically during the last few decades (Brodersen, Steptoe, Boniface, \& Wardle, 2007) and represents a clear threat to health both in developed and developing countries. In the research on physical fitness and sports lifestyle conducted and published by the International Council of Sport Science and Physical Education (Telama, Naul, Nupponen, Rychtecký, \& Vuolle, 2002), with the participation of over 60,000 respondents aged 12 to 15 years from six European countries, participating in sports as a form of recre- 
ation was ranked 6th, while the same study ranked participation in organized competitive sports as 9th on the list of leisure activities.

Regular physical activity is a key determinant for energy consumption and is of fundamental importance for the energy balance and body weight control. It also reduces the risk of cardiovascular and cerebrovascular diseases, diabetes, breast cancer and colon cancer, depression... Therefore, the World Health Organization recommends 30 minutes of physical activity of moderate intensity (National Health Survey Serbia, 2014).

A study conducted in the US (Bammel \& BurrusBammel, 1992) showed that young people spend up to six hours a day in front of TV and sleeping is the only activity that young Americans practiced more than watching TV, and research from Poland (Drygas, Kwasniewski, Kaleta; \& Ruszkowski-Majzel, 2008) has shown that over $50 \%$ of young people between 15 and 19 years of age do not participate in any sports or recreational activity but spend 15 hours a week in activities that do not demand any physical activity. According to the research performed by the Institute for Public Health "Dr Milan Jovanovic Batut" in 2006, almost one-fifth of children and adolescents aged 7-19 in Serbia (18\%) were moderately obese and obese, which is an increase compared to 2000 . The increase in the number of moderately obese and obese children in Serbia is the result of bad eating habits and lack of physical activity. The incidence of obesity, according to UNICEF data from 2007 in children under five years of age in Serbia, is 15\% (Đokić, Međedović, \& Smiljanić, 2011).

Positive aspects of regular physical activity can be seen on physical and mental health, and psychosocial development. It's never too early to start adopting healthy habits and education about the importance of physical activity: studies show that the majority of children engaged in sports and physically active in childhood, also keep these habits later when they grow up. Sport has a positive effect on development of personality - children engaged in some sporting activity during the early age develop good work habits and self-discipline early in their life. Sport on the other hand has a positive role in the emotional development of children since it facilitates the process of their socialization. There are many reasons in favor of sports. Sport and physical activity may prevent the excessive obesity in childhood and of course in adulthood. Sport and physical activity help in developing self-awareness and reduce anxiety and stress. Sport teaches a child both how to surpass and to accept defeat and it teaches it fair play in the game and in life, and leads to developing friendships.
Regarding young people, sports programs lead to the development of skills, teamwork, self-discipline, better socialization in the society. The world is facing new challenges to maintain and improve the health of people. The way of life has changed in the developed world. A better standard of living has not been used for the advancement and improvement of health and therefore we are exposed to threats of new pandemics of non-communicable diseases such as obesity, heart disease and vascular disease, diabetes, cancer, osteoporosis.

On the basis of this conclusion we come to the basic problem of this research and these are the morphological characteristics and motor abilities of physically active and inactive female high-school students. Starting from the basic problem, the subject of this paper is the difference in morphological characteristics and motor abilities of physically active and inactive female high-school students. The purpose of our study was to analyze morphological and motor variables in physically active and inactive female highschool students with the aim to determine whether there are statistically significant differences between the two groups.

This work provides answers for the two following questions: there are statistically significant differences in morphological characteristics of physically active and inactive female students, and there are statistically significant differences in motor skills of physically active and inactive female students.

\section{METHODS}

\section{Sample of respodents}

\section{Sample of respondents}

The total sample in this study consists of 72 female students from high school "Svetozar Miletic" from Novi Sad, aged $18 \pm 6$ months, who were divided into two groups: the first group consists of 36 female students who are considered to be physically active (minimum 30 minutes a day of practicing physical activity of moderate intensity) and the second group consists of 36 female students who are considered to be insufficiently physically active (under 30 minutes).

\section{Sample of variables}

In order to determine the morphological status and level of motor abilities of female students, with the aim of monitoring and comparing the results, four morphological characteristics were measured for all students in the sample: body height (anthropometer by Martin), body weight, body fat percentage, 
muscle mass percentage (body composition determining system, Omron BF511). Body mass index BMI is calculated using a simple mathematical formula that shows the relationship between weight and height:

$$
\text { BMI = body weight }(\mathrm{kg}) / \text { body height }^{2}(\mathrm{~m})
$$

The motor skills were evaluated using the Eurofit battery (Nićin, 2000) composed of eight tests: flamingo balance test, hand taping, sit-and-reach, standing broad jump, trunk lifting, bent arm hang, 10x5 m shuttle run, $20 \mathrm{~m}$ endurance shuttle run.

\section{Description of the measurement procedure}

All tests were performed in the morning during physical education class in the gym on working days. Testing was conducted by five examiners, professors of physical education. Anthropometric measurements were performed immediately before checking physical abilities. In the first half of the testing period (the first class) anthropometric measurements and tests of balance, flexibility and strength were conducted, while during the second class tests of speed and endurance were performed.

\section{Data processing methods}

This study had a transversal character. The data obtained in the survey were analyzed using descriptive and comparative statistics. Regarding the domain of descriptive statistics the mean value, minimum, maximum, and standard deviation were shown. The Kolmogorov-Smirnov test was used to determine the normality of distribution, while, regarding the domain of comparative statistics, multivariate analysis of variance (MANOVA) and univariate analysis of variance (ANOVA) were used to determine the significance of differences between arithmetic means of the respondents.

\section{RESULTS AND DISCUSSON}

In accordance with previously established research objective, the thematic unit of morphological characteristics of girls in relation to the level of physical activity will be analyzed in Table 1 . The analysis will be conducted on the following morphological characteristics: body height, body weight, body mass index, $\%$ of body fat, $\%$ of muscle mass. The descriptive parameters of morphological variables in physically active and inactive female students indicate that there are no statistically significant deviations from the normal distribution in all variables, which was suggested by the results of Kolmogorov-Smirnov (KS) test.

By examining the mean values of the results it was observed that the results regarding growth and development are within expected limits of the reasonably possible values for the studied age as indicated by Rakić (2009, 2010) and Pavlica (2012). The average height of physically active girls is $156 \mathrm{~cm}$, while the average height of physically inactive girls is $166.4 \mathrm{~cm}$ which, compared with research results from Rakić

TABLE 1

Descriptive statistics of morphological variables for physically active (1) and physical inactive (2) female students.

\begin{tabular}{lccrccr}
\hline Varables & Group & M & Min & Max & SD & \multicolumn{1}{c}{ K-S } \\
\hline \multirow{2}{*}{ BH } & 1 & 156.00 & 155.40 & 181.30 & 59.31 & .94 \\
\cline { 2 - 7 } & 2 & 166.40 & 155.40 & 179.00 & 63.71 & .65 \\
\hline \multirow{2}{*}{ BW } & 1 & 45.20 & 48.10 & 76.90 & 75.17 & .97 \\
\cline { 2 - 7 } & 2 & 59.10 & 48.10 & 71.70 & 71.31 & .63 \\
\hline \multirow{2}{*}{ BMI } & 1 & 17.50 & 21.80 & 27.70 & 2.29 & .88 \\
\hline \multirow{2}{*}{ BFP } & 2 & 21.30 & 17.30 & 26.70 & 2.22 & .98 \\
\hline \multirow{2}{*}{ BMMP } & 1 & 17.40 & 28.40 & 40.50 & 5.76 & .70 \\
\cline { 2 - 7 } & 2 & 29.60 & 7.30 & 42.80 & 6.43 & .95 \\
\hline
\end{tabular}

Legend: M - Mena; Min - Minimum; Max - Maximum; SD - Standard deviation; K-S - Statistcal signficance by Kolmogorov-Smirnov test; BH - Body height; BW - Body weight; BMI - Body mass index; BFP - Body fat percentage; BMMP - Body muscle mass percentage. 
(2009) in which it was found that the average height in the 17th year was $167.2 \mathrm{~cm}$ and in the 18th 167.4 $\mathrm{cm}$, is similar to results of this research. The average value of body weight in physically active girls is 45.1 $\mathrm{kg}$ while the average weight in physically inactive girls is $59.1 \mathrm{~kg}$. In Rakić (2009) average weight for age of 17 years was $60.58 \mathrm{~kg}$ and for age of $18,62.16 \mathrm{~kg}$. Similar values regarding the average results were obtained in studies by Pavlica (2012) and Rakić (2010). The analysis of the minimum and maximum results of all the variables do not show some significant individual differences in the variables for the assessment of the morphological status of the students.

Further analysis of differences between minimum and maximum values between groups reveals that the group 1 - physically active female students have higher values than the group 2 -physically inactive female students in almost all variables, except for the variable (BMI) Body mass index for which second group has higher results for minimum and maximum values. The percentage of body fat is higher (BFP), i.e. the results are also higher for second group: 42.8 , but it represents the worst result since this is an inverse variable (the higher percentage - the worse result).
Table 2 shows the results of motor tests for both groups of respondents in the area of basic motor skills. The descriptive parameters of morphological variables for physically active and inactive female students indicate that there are no statistically significant deviations from the normal distribution in all variables, which is also shown by the results of $\mathrm{KS}$ test. Examining the mean values of the results reveals that the results are in realistic boundaries. The analysis of the minimum and maximum results for some variables (flamingo test - FLAM, bent arm hang $\mathrm{BAH}$, shuttle run - SHR, endurance shuttle run ESHR) shows a greater range of values for variables used for assessing the motor status of female students

Further analysis of minimum and maximum values among groups reveals that the group 1 - physically active female students, have higher values than the group 2 - physically inactive female students regarding most of the variables, except for the variables: flamingo test FLAM, hand tapping HTAP and shuttle run SHR, with higher values for the second group, which was the worse result since this is an inverse variable (the higher value - the worse result). Greater value is achieved by group 2 only for a

TABLE 2

Descriptive statistics of motor variables for physically active (1) and physically inactive (2) female students.

\begin{tabular}{lrrrrrr}
\hline Varables & Group & \multicolumn{1}{c}{ M } & \multicolumn{1}{c}{ Min } & \multicolumn{1}{c}{ Max } & \multicolumn{1}{c}{ SD } & \multicolumn{1}{c}{ K-S } \\
\hline \multirow{2}{*}{ FLAM } & 1 & 9.74 & 1.00 & 21.00 & 4.69 & .70 \\
\cline { 2 - 7 } & 2 & 15.26 & 4.00 & 30.00 & 7.75 & .04 \\
\hline \multirow{2}{*}{ HTAP } & 1 & 130.62 & 108.00 & 167.00 & 15.60 & .96 \\
\cline { 2 - 7 } & 2 & 142.24 & 114.00 & 183.00 & 16.43 & .77 \\
\hline \multirow{2}{*}{ SAR } & 1 & 609.12 & 430.00 & 770.00 & 91.00 & .76 \\
\cline { 2 - 7 } & 2 & 545.79 & 320.00 & 710.00 & 85.57 & .66 \\
\hline \multirow{2}{*}{ SBJ } & 1 & 171.74 & 149.00 & 200.00 & 14.24 & .31 \\
\hline \multirow{2}{*}{ TRL } & 2 & 150.63 & 74.00 & 202.00 & 27.44 & .99 \\
\hline \multirow{2}{*}{ BAH } & 1 & 24.03 & 19.00 & 32.00 & 3.43 & .67 \\
\cline { 2 - 7 } & 2 & 19.13 & 14.00 & 29.00 & 3.06 & .72 \\
\hline \multirow{2}{*}{ SHR } & 1 & 307.71 & 81.00 & 754.00 & 186.11 & .40 \\
\hline \multirow{2}{*}{ ESHR } & 1 & 114.24 & 10.00 & 411.00 & 91.21 & .16 \\
\cline { 2 - 7 } & 2 & 215.79 & 185.00 & 239.00 & 12.48 & .87 \\
\hline
\end{tabular}

Legend: M - Mena; Min - Minimum; Max - Maximum; SD - Standard deviation; K-S - Statistcal signficance by Kolmogorov-Smirnov test; FLAM - Flamingo balance test; HTAP - Hand taping; SAR - Sit-and-reach; SBJ - Standing broad jump; TRL - Trunk lifting; BAH - Bent arm hang; SHR - 10x5 meter shuttle run; ESHR - 20 meters endurance shuttle run. 
maximum result for variable standing broad jump SBJ (202).

By analyzing the differences between the morphological characteristics of the system variables from the two groups, based on the results of multivariate analysis of variance, significance level of $p=.02$, one can conclude that there is a statistically significant difference between these groups regarding the total system of variables, Table 3 . Based on the values obtained by the univariate analysis of variance and values of $\mathrm{F}$ relation of univariate test, it can be concluded that between physically active and physically inactive girls regarding the morphological status, there are statistically significant differences only regarding one variable: the percentage of muscle mass (BMMP), at the level of $p=.01$, while no statistically significant differences $(p>.05)$ were found for other variables.
The results of multivariate analysis of variance for eight of the observed characteristics of the motor space, with a significance level of $p=.00$, indicate that there are statistically significant differences in the level of motor skills among physically active and physically inactive female students. The analysis of individual variables from univariate analysis of variance for eight of the observed characteristics of the motor space, found that there are statistically significant differences in the level of motor skills between physically active and physically inactive female highschool student for all variables at the level of $p<.05$.

Physical fitness has proved to be an important factor when it comes to public health both in grownups (Mette, Talbot, Schrager, \& Conwit, 2002; Venn et al, 2007) and in children and adolescents (Ortega et al., 2008; Ortega, Ruiz, Castillo, \& Sjostrom, 2008;

TABLE 3

Differences in individual variables regarding the morphological status of physically active (1) and physically inactive (2) female students (ANOVA).

\begin{tabular}{lrrrr}
\hline Varables & $\mathrm{M}_{\mathrm{SV} 1}$ & \multicolumn{1}{c}{$\mathrm{M}_{\mathrm{SV} 2}$} & \multicolumn{1}{l}{$F$} & \multicolumn{1}{l}{$p$} \\
\hline $\mathrm{BH}$ & 156.00 & 166.00 & .18 & .67 \\
\hline $\mathrm{BW}$ & 45.20 & 59.10 & .31 & .58 \\
\hline BMI & 17.50 & 21.30 & .83 & .37 \\
\hline BFP & 17.40 & 29.60 & .73 & .40 \\
\hline BMMP & 25.90 & 28.50 & 8.07 &. $\mathbf{0 1}$ \\
\hline
\end{tabular}

Legend: $\mathbf{M}_{\mathrm{sv1}}$ - Mena group 1; $\mathbf{M}_{\mathrm{sv} 2}$ - Mena group 2; F - Tabular value of Fischer distribution; p - Probibility; BH - Body height; BW - Body weight; BMI - Body mass index; BFP - Body fat percentage; BMMP - Body muscle mass percentage; $F=2.70 ; p=$ .02 .

De Bourdeaudhui, 1998; Sallis, 1994; Sallis et al, 1992). All studies have shown that the time spent in physical activity among adolescents is reduced, and that the time spent in sedentary lifestyle increases (Nader, Bradley, Houts, McRitchie, \& O'Brien, 2008), and both trends are more pronounced in girls (Brettschneider et al., 2010; Silva et al., 2010; Troiano et al., 2008), followed by the deterioration of their physical condition, especially endurance and strength (Beunen et al., 1992; Froberg \& Andersen, 2010; Tomkinson \& Olds, 2007; Westerståhl, Barnekow-Bergkvist, \& Jansson, 2005) and in activities that require running capacity (Froberg \& Andersen, 2010; Tomkinson \& Olds, 2007; Wedderkopp, Froberg, Hansen, \& Andersen, 2004).

The analysis of mean values shows us that the group 1 - physically active female students showed significantly better results in all respects of motor space compared to group 2 - physically inactive female students.
In accordance with the recommendations of the "President's Council on Physical Fitness and Sports" (Department of Health and Human Services, 2008) children and teenagers need 60 minutes of physical activity of moderate intensity daily in order to reach the consequent beneficial effects on their health. A similar recommendation was given by the World Health Organization: (a) children and young people aged 5 to 17 years should have at least 60 minutes of moderate to intense physical activity daily; (b) more than 60 minutes of physical activity provides the added benefit for the health of young people; (c) the greater part of the daily physical activities should be of aerobic character while more intensive activities, including those that develop strength and strengthen bones, should be included at least three times a week (Global Recommendations on Physical Activity for Health, 2011). Population studies show that many young people do not meet this requirement. Although 
TABLE 4

Descriptive statistics of motor variables for physically active (1) and physically inactive (2) female students.

\begin{tabular}{lrrrr}
\hline Varables & $\mathrm{M}_{\mathrm{SV} 1}$ & \multicolumn{1}{c}{$\mathrm{M}_{\mathrm{SV} 2}$} & \multicolumn{1}{c}{$F$} & \multicolumn{1}{l}{$p$} \\
\hline FLAM & 9.74 & 15.26 & 13.03 & $\mathbf{. 0 0}$ \\
\hline HTAP & 130.62 & 142.24 & 9.42 & $\mathbf{. 0 0}$ \\
\hline SAR & 609.12 & 545.79 & 9.26 & $\mathbf{. 0 0}$ \\
\hline SBJ & 171.74 & 150.63 & 16.19 & $\mathbf{. 0 0}$ \\
\hline TRL & 24.03 & 19.13 & 40.98 & $\mathbf{. 0 0}$ \\
\hline BAH & 307.71 & 114.24 & 32.41 & $\mathbf{. 0 0}$ \\
\hline SHR & 197.35 & 215.79 & 37.65 & $\mathbf{. 0 0}$ \\
\hline ESHR & 665.29 & 362.11 & 56.22 & $\mathbf{. 0 0}$ \\
\hline
\end{tabular}

Legend: $\mathbf{M}_{\mathrm{sv} 1}$ - Mena group 1; $\mathbf{M}_{\mathrm{sv} 2}$ - Mena group 2; $\mathbf{F}$ - Tabular value of Fischer distribution; p - Probibility; FLAM - Flamingo balance test; HTAP - Hand taping; SAR - Sit-and-reach; SBJ - Standing broad jump; TRL - Trunk lifting; BAH - Bent arm hang; SHR - 10x5 meter shuttle run; ESHR - 20 meters endurance shuttle run.

$80 \%$ of adolescents are physically active 30 minutes a day, less than half of them are active 60 minutes (Pate, Longi, \& Heath, 1994).

Children spend more time than ever in institutions such as schools (Rønning, 2001) which itself results in less physical activity. School requirements also get bigger, often at the expense of physical education classes, although all studies suggest that physical activity is associated with better success in school (Brettschneider et al., 2004). In addition, in many European countries, young people walk or ride a bicycle to school lesser and lesser, and this is particularly evident in large cities (European Common Indicators, 2003).

Organized classes of physical education are one of the strategies to increase the level of recommended physical activity for children and adolescents (McKenzie et al., 2004; Task Force on Community Preventive Services, 2002).

\section{CONCLUSON}

In accordance with the objectives of the research we tested the differences between groups of female students who are engaged in any mode of physical activity of moderate intensity (sports games, recreation programs, skating, aerobics programs, etc.) and who are considered to be physically active (minimum 30 minutes of practice a day) and insufficiently physically active female students (below average).

Based on the results of the morphological status research, differences have been found between the groups at the level of $p=.02$. By analyzing some individual variables it can be concluded that in only one variable, there is a statistically significant differ- ence: the percentage of body muscle mass (BMMP), at the level of $p=.00$, which is in some way a logical conclusion, because the muscle growth requires some stimulus, such as a physical exercise. Physical exercise increases the strength and endurance of muscles and therefore muscle mass is increased. In addition to physical activity, increasing of the muscle mass is largely affected by food, i.e. adequate intake of calories, carbohydrates and proteins. No statistically significant differences at $p<.05$ were observed regarding other variables. From the table of descriptive characteristics it can be observed that the Body Mass Index (BMI) and body fat percentage (BFP) are moving in a slightly larger borders and that both groups belong to the pre-obese and obese categories, i.e. they have excess body fat. The causes of obesity are complex and numerous, but one of the strongest predictors of obesity is genetic predisposition so excess body fat in these groups can be attributed to this factor and also the fact that many changes occur during puberty, both in mental and physical development.

Multivariate analysis of the system of motor skills among the groups found statistically significant differences at the level of $p=.00$, while the analysis of individual variables shows us that there are statistically significant differences among the groups for all the individual variables, as can be seen in Table 4 . There are many reasons that support engagement in physical activities. These differences indicate how much physical activity and sport play an important role in the development of motor skills in adolescents as well as all other aspects that emerge from it (enhanced cardio-respiratory function, disease prevention, emotional stability, social and mental welfare, etc.). 


\section{REFERENCES}

Bammel, G., \& Burrus-Bammel, L. L. (1992). Leisure and human behavior. Dubuque, IA: Wm.C.Brown Publishers.

Beunen, G., Lefevre, J., Claessens, A., Lysens, R., Maes, H., Renson, R., (1992). Age-specific correlations analyses of longitudinal physical fitness in men. European Journal of Applied Physiology and Occupational Physiology, 64, 538-545. doi: 10.1997/BF00843765

Brettschneider, W., Neal, R., Armstrong, N., Diniz, J., Froberg, K., \& Laakso, L. (2004). Study on young people's lifestyle and sedentariness and the role of sport in the context of education and as a means of restoring the balance. Paderborn, Germany: EC, Directorate-General for Education and Culture, Unit Sport.

Biddle, S. J., \& Asare, M. (2011). Physical activity and mental health in children and adolescents: A review of reviews. BrJ Sports Med, 45(11), 886895. doi: 10.1136/bjsports-2011-090185.

Blair S. (2005). Physical inactivity: The major public helth problem in 21 st century. In: D. Milanović and F. Prot (Eds.), Proceedings of 4th International Scientific Conference of Science and profession: Challenge of future (p. 22). Opatija. Croatia. Zagreb: Fakulty of Kinesiology, University of Zagreb. PMid: 1560126

Bouchard, C., Blair, S. N., \& Haskel, W. L. (2012). Physical activity and health. 2nd ed. Champaign, IL: Human Kinetics.

Brodersen, N. H., Steptoe, A., Boniface, D. R., \& Wardle, J. (2007). Trends in physical activity and sedentary behaviour in adolescence: Ethnic and socioeconomic differences. Br J Sports Med., 41, 140-144. doi: 10.1136/bjsm.2006.031138

Byrne, A, \& Byrne, D. G. (1993). The effect of exercise on depression, anxiety, and other mood states: A review. J Psychosom Res., 37, 565-574. doi: 10.1016/0022-3999(93)90050-P

Camero, M., Hobbs, C., Stringer, M., Branscum, P., \& Taylor, L. (2012). A review of physical activity interventions on determinants of mental health in children and alolescentes. International Journal of Mental Health Promotion, 14, 196-206. doi: 10.1080/14623730.2012.752901

De Bourdeaudhui I. (1998). Behavioural factors associated with physical activity in young people. In: S. Biddle, J. Sallis, and N. Cavill (Eds.), Young and active? Young people and health-enhancing physical activity: Evidence and implications. London, Unted Kingdom: Health Education Authority.
Department of Health and Human Services: The President's Council on Physical Fitness and Sport. (2008). Physical activity facts. Rockville, MD: The President's Council on Physical Fitness and Sport; 2008. Retrived from http://www. fitness. gov/resources_factsheet.htm.

Drygas, W,. Kwaśniewska, M., Kaleta, D., \& Ruszkowska-Majzel, J. (2008). Increasing creational and leisure time physical activity in Poland - how to overcome barriers of inactivity. Journal of Public Health, 16(1), 31-36. doi: 10.1007/s10389-0070151-z

Đokić, Z., Međedović, B., \& Smiljanić, J. (2011). Stanje uhranjenosti, posturalni status i kvalitet sprovođenja nastave fizičkog vaspitanja u osnovnim školama. TIMS Acta, 5, 10-19

European common indicators: Towards a local sustainability profile (Indicator 6 - Children's journeys to and from school). (2003). Milan, Italy: Ambiente Italia Research Institut.

Froberg, K., \& Andersen, L. B. (2010). The importance of physical activity for childhood health. In: M. Kovač, and G. Jurak (Eds.), Proceedings of the Fifth International Congress Youth Sport. Ljubljana, Slovenia: Faculty of Sport, University of Ljubljana. PMCid: PMC3048259

Global recommendations on physical activity for health: 5-17 years old. (2011). Geneva: World Health Organization; Retrived from http:// www.who.int/dietphysicalactivity/physicalactivity-recommendations-17years.pdf?ua $=1$

Guthold, R., Cowan, M. J., Autenrieth, C. S., Kann, L., Riley, L. M. (2010). Phyisical activity and sedentary behavior among schoolchildren: A 34 - country comparison. J Pedatr, 157(1), 43-49. doi: 10.1016/j.jpeds.2010.01.019

Hallai, P. C., Andersen, L. B., Bull, F. C., Guthold, R., Haskell, W., \& Ekelund, U. (2012). Global physical activity levels Surveillance progress, pitfalls, and prospects. Lancet, 380(9838), $247-$ 257. doi: 10.1016/S01406736(12)60646-1

Heyward, V. H. (1991). Advanced fitness aassessment andexercise prescription. 2nd ed. Champaign, IL: Human Kinetics.

Malina, R., Bouchard, C., \& Baror, O. (2004). Growth, maturation, and physical activity. 2nd ed. Champaign, IL: Human Kinetics.

Mckenzie, T. L., Sallis, J. F., Prochaska, J. J., Conway, T. L., Marshall, S. J., \& Rosengard, P. (2004). Evaluation of a two-year middle-school physical education intervention: M-SPAN. Med Sci Sports Exerc, 36, 1382-1388. doi: 10.1249/01. MSS.0000135792.20358.4D 
Metter, E. J., Talbot, L. A., Schrager, M., \& Conwit, R. (2002). Skeletal muscle strength as a predictor of all-cause mortality in healthy men. $J$ Gerontol A Biol Sci Med Sci., 7(10), B359-B365. doi: 10.1093/gerona/57.10.B359

Nader, P. R., Bradley, R. H., Houts, R. M., McRitchie, S. L., \& O’Brien, M. (2008).

Moderate-to-vigorous physical activity from ages 9 to 15 years. $J A M A, 300(3), 295-305$. doi: 10.1001/jama.300.3.295

National Healt Survey Serbia. (2014). Republic of Serbia: Ministry of health. Retrived from http://www.batut.org.rs/download/publikacije/ IstrazivanjeZdravljaStanovnistvaRS2013.pdf

Nićin, Đ., (2000). Antropomotorika. Novi Sad, Serbia: Fakultet fizičke kulture.

Ortega, F. B, Artero, E. G., Ruiz, J. R., VicenteRodriguez, G., Bergman, P., \& Hagstromer, M. (2008). Reliability of health-related physical fitness tests in European adolescents. Int J Obes., 32(Suppl. 5), S49-S57. doi: 10.1038/ijo.2008.183

Ortega, F. B., Ruiz, J. R., Castillo, M. J., \& Sjostrom, M. Physical fitness in childhood and adolescence: A powerful marker of health. Int J Obes., 32(1), 1-11. doi: 10.1038/sj.ijo.0803774

Pate, R. R., Long, B. J., \& Heath, G. (1994). Descriptive epidemiology of physical activity in adolescents. Pediatr. Exerc. Sci., 6, 434-447.

Pavlica, T., Rakić, R., Djuričanin, A., Korovljev, D., \& Srdić, B. (2012). Growth and Nutritional Status of Childred and Adolescents from 7 to 19 Years of Age in the Town of Jagodina (Central Serbia). HealthMED, 6(1), 284-292.

Plonczynski, D. J. (2000). Measurement of motivation for exercise. Health Educ Res., 15, 695-705. doi: 10.1093/her/15.6.695

Rakić, R. (2009). Značaj nekih faktora sredine na rast $i$ razvoj dece $i$ adolescenata u Vojvodini [The importance of some environmental factors on the growth and development of children and adolescents in Vojvodina]. Unpublish doctoral dssertation, University of Novi Sad, Prirodnomatematički fakultet, Departman za biologiju i ekologiju.

Rakić, R., Božić-Krstić, V., \& Pavlica, T. (2010). Age changes in height, weight and nutritional condition in adolescents from Novi Sad. Acta morphologica et antropologica, 15, 217-219.

Rønning, E. (2001). Living conditions of children before and now. Oslo, Swiden: Statistisk Sentralbyrĺ. Retrived from http://www.ssb.no/vis/ samfunnsspeilet/utg/200104/01/art-2001-0920-01.html.
Sallis, J. F. (1994). Determinants of physical activity behavior in children. In: R. R. Pate, and R. C. Hohn (Eds.), Health and Fitness through Physical Education. Champaign, IL: Human Kinetics.

Sallis, J. F., Simons-Morton, G., Stone, E. J., Corbin, C. B., Epstein, L. H., Faucette, N. (1992).

Determinants of physical activity and interventions in youth. Med. Sci.Sports Exerc., 24, S248 -S257. doi: 10.1249/00005768-19920600100007

Silva, P., Sousa, M., Aires, L., Seabra, A., Ribeiro, J., Welk, G. (2010). Physical activity patterns in Portuguese adolescents: The contribution of exra-curricular sports. European Physical Education Review, 16(2), 171-181. doi: 10.1177/1356336X10381305

Task Force on Community Preventive Services. (2002). Recommendations to increase physical activity in communities. Am J Prev Med, 22, 6772. doi: 10.1016/S0749-3797(02)00433-6

Telama, R., Naul, R., Nupponen, H., Rychtecký, A., \& Vuolle, P. (2002). Physical fitness, sporting lifestyles, and Olympic ideals: cross-cultural studies on youth sport in Europe. Schorndorf, Germany: Karl Hofmann.

Tomkinson, G. R., \& Olds, T. S. (2007). Secular changes in pediatric aerobic fitness test performance: The global picture. Med Sport Sci., 50, 46-66. doi: 10.1159/000101075

Troiano, R. P., Berrigan, D., Dodd, K. W., Masse, L. C., Tilert, T., McDowell, M. (2008). Physical activity in the United States measured by accelerometer. Med Sci Sports Exerc, 40(1), 181188. doi:10.1249/mss.0b013e31815a51b3

Venn, A. J., Thomson, R. J., Schmidt, M. D., Cleland, V. J., Curry, B. A., \& Gennat, H. C. (2007). Overweight and obesity from childhood to adulthood: a follow-up of participants in the 1985 Australian Schools Health and Fitness Survey. Med J Aust., 186(9), 458-460. PMid: 17484707

Weinberg, R. S., \& Gould, D. (2007). Foundations of sport and exercise psychology. 4th ed. Champaign, IL: Human Kinetics.

Westerståhl, M., Barnekow-Bergkvist, M. M., \& Jansson, E. (2005). Low physical activity among adolescents in practical education. Scandinavian Journal of Medicine \& Science in Sports, 15(5), 287297. doi: 10.1111/j.1600-0838.2004.00420.

WHO. (2012). Ageing and Life Course, Geneva. Retrived from http://www.who.int/ageing/ about/facts/en/.

Wedderkopp, N., Froberg, K., Hansen, H. S., \& Andersen, L. B. (2004). Secular trends in 
physical fitness and obesity in Danish 9-year-old girls and boys: Odense school child study and Danish substudy of the European youth heart study. Scand J Med Sci Sports., 14(3), 150-155. doi: 10.1111/j.1600-0838.2004.00365.x

Received: December 30, 2014

Revision received: May 25, 2015

Accepted: Jun 15, 2015

Correspondence to: Marijana Simić, MSC

Faculty of Sport and Physcal Educaton Lovćenska 16, 21000 Novi Sad

Serbia

Phone: 00381643656295

E-mail:marijanas15@gmail.com 